\title{
PERIOPERATIVE CARDIAC ARRHYTHMIAS: AN APPROACH
}

Savitri D. Kabade ${ }^{1}$, Gowri Shankar B², Venkatesh Y3

\section{HOW TO CITE THIS ARTICLE:}

Savitri D. Kabade, Gowri Shankar B, Venkatesh Y. "Perioperative Cardiac Arrhythmias: An Approach". Journal of Evolution of Medical and Dental Sciences 2014; Vol. 3, Issue 37, August 21; Page: 9633-9647,

DOI: $10.14260 /$ jemds/2014/3247

INTRODUCTION: Cardiac arrhythmias are common and an important cause of morbidity and mortality in the perioperative period. Given improvements made in the management of cardiac arrhythmias, a greater breadth of therapeutic options with currently available ranging from pharmacologic and nonpharmacologic therapies to implantable defibrillators. However the underlying principle is immediate diagnosis and intervention with appropriate therapy which will often prevent an arrhythmia into a life-threatening event.1,2,3

DEFINITION: Arrhythmia is defined as "Abnormality of cardiac rate, rhythm or conduction which can be either lethal or symptomatic (syncope, dizziness, or palpitations) or asymptomatic." 4

INCIDENCE: The incidence has been reported to vary from 16.3 to $61.7 \%$ in patients undergoing noncardiac surgery, while patients undergoing cardiac surgery have reported incidence of more than $90 \%{ }^{4}$ Peri-operative arrhythmias after non-cardiac thoracic surgery has incidence of $18 \%$, with atrial fibrillation (AF) being the most common.

\section{PATHOGENESIS}

1. Injury or damage (pathology): To the cardiac conduction systems.

2. Re-Entry: Re-entry is a mechanism that may precipitate a wide variety of supraventricular and ventricular arrhythmias. Re-entry requires two pathways that have heterogeneous electrophysiologic properties which allows conduction to block in one pathway and propagate slowly in the other, allowing for sufficient delay so that the blocked site has time for recovery to allow for re-entry or circus movement tachycardia. Shown is a typical schema for re-entry in the AV node. ${ }^{3}$

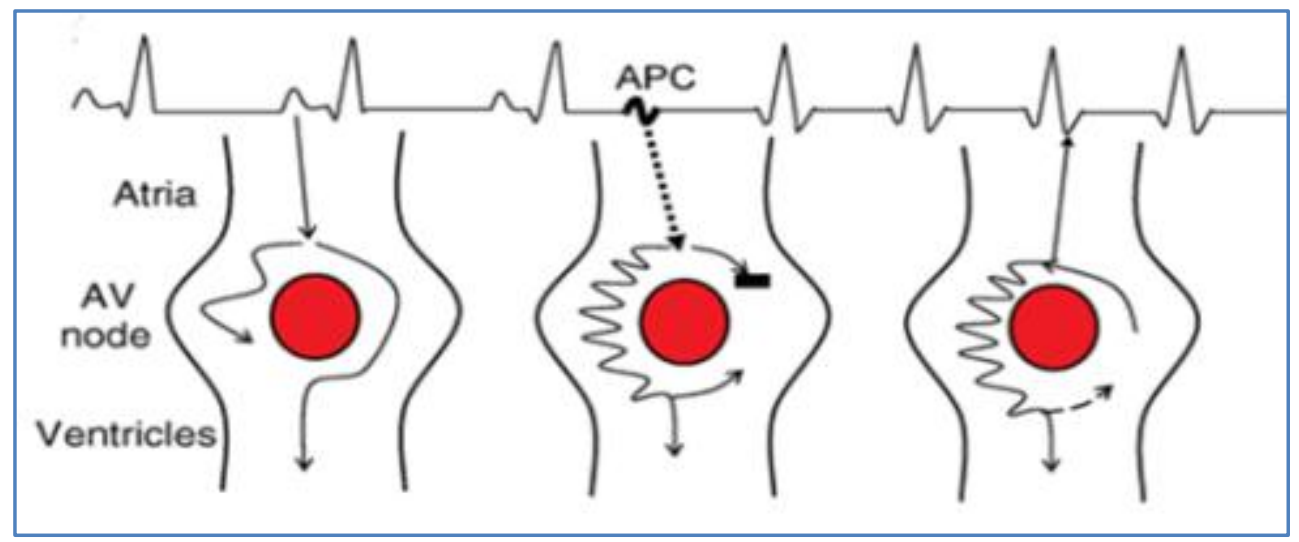

3. Automaticity: Abnormal depolarization of atrial or ventricular muscle cell during the periods of action potential can lead to arrhythmias. 
4. Mutations in ion Channels:

5. Ectopic foci/ irritable Foci:

a) Increased automaticity due to reduced threshold potential or an increased slope of phase 4 depolarization.

b) Triggered activity due to 'after' depolarization's reaching threshold potential.4,6

\section{CLASSIFICATION:}

A. Arrhythmias seen during the peri-operative period can be broadly classified

a. depending on their rate as Bradyarrhythmias $(<60 \mathrm{bpm})$ and Tachyarrhythmias $(>100 \mathrm{bpm})$.

b. Depending on the site of origin of the arrhythmia:

1. Sinus arrhythmias - Sinus Bradycardia, Sinus tachycardia.

2. Supraventricular arrhythmias - Supraventricular tachycardia (PSVT), atrial flutter and atrial fibrillation.

3. Ventricular arrhythmias - Ventricular tachycardia, Ventricular flutter and Ventricular fibrillation.

4. Heart blocks:
a) Sino atrial blocks.
b) Atrioventricular Blocks - First, Second and Third degree.
c) Bundle Branch Blocks - Right and Left.

\section{Contributing Factors and Causes of Preoperative Arrhythmias:}

\section{Patient Related Factors:}

a. Pre-existing cardiac disease - The patients with known cardiac disease, thyrotoxicosis, have much higher incidence of arrhythmias during anaesthesia and are often fatal. Anxiety, excessive consumption of caffeine, alcohol and smoking, are known to precipitate arrhythmias

b. Central nervous system disease - Patients with intracranial disease especially subarachnoid haemorrhage may show ECG abnormalities such as changes in QT intervals, development of Q waves, ST-segment changes, and occurrences of $U$ waves.

c. Old age -. Aging causes degenerative change in atrial anatomy and is accompanied by relative changes in atrial pathology. The injury to sympathovagal fibers of cardiac plexus during surgery and pre-existing atrial electrical changes in these patients predispose them to postoperative atrial fibrillation.

\section{Anaesthesia Related Factors:}

a. Direct laryngoscopy and Tracheal intubation - It is one of the most noxious stimuli leading to arrhythmias during induction as well as during the perioperative period and often associated with haemodynamic disturbances.

b. General anaesthetics - The drugs used for general anaesthesia are not primarily arrhythmogenic, but arrhythmias can be produced in the presence of a variety of triggering agents and clinical situations generating high catecholamines such as light plane of anaesthesia with hypertension and tachycardia, hypoxemia, hypercarbia, exogenous epinephrine and aminophylline. 
c. Local anaesthesia - Regional anaesthesia especially central neuraxial blockade may be associated with pharmacological sympathectomy leading to parasympathetic nervous system predominance causing bradyarrhythmias.

d. Electrolyte imbalance and abnormal arterial blood gases - Hypokalemia or hyperkalemia, hyponatraemia, hypomagnesaemia may lead to arrhythmias. Abnormal blood gases such as hypercarbia, hypoxemia or electrolyte imbalance produce arrhythmias either by producing reentrant mechanism or by altering depolarization of conducting fibers.

e. Central venous cannulation- Stimulation of carotid sinus reflexes due to pressure from fingers during jugular vein cannulation and excess insertion of the central venous catheter into the right atrium may also lead to arrhythmias.

\section{Surgery Related Factors:}

a. Cardiac surgery - A spectrum of cardiac arrhythmias can be observed during the immediate period following the release of aortic cross clamp when myocardium is recovering from the ischaemic insult and regaining normal sinus rhythm. Surgical manipulation such as retraction of the heart during operation on beating heart, venous cannulation or taking sutures over the atrium can also precipitate arrhythmias.

b. Non-cardiac surgery -Vagal stimulation due to traction on the peritoneum or direct pressure on the vagus nerve during carotid artery surgery may produce bradycardia or atrioventricular (AV) blocks, or even asystole. Dental surgery and laparoscopic surgery causes profound stimulation of both parasympathetic and sympathetic nervous stimuli. Perioperative arrhythmias after non-cardiac thoracic surgery are commonly supraventricular in origin, affecting $18-20 \%$ of the cases. $4,5,7$

Diagnostic Evaluation: The prevention of peri-operative arrhythmias is of paramount importance and demands the following factors to be considered:

1. A proper pre-operative history of heart disease, lung disease and drug intake is to be elicited and detailed physical examination to exclude these illnesses is necessary.

2. Investigations include 12 lead EKG, 2D echo and estimation of serum electrolytes and oxygen saturation in arterial blood and correction of abnormalities, if any. Verification of renal and liver function is important in patients on medications which can cause arrhythmias; doses should be titrated whenever necessary.

3. Choice of an appropriate anaesthetic agent and technique should be done after the preoperative assessment taking into consideration the above mentioned factors and diseases.

4. Ideally, all patients should be monitored for arrhythmias during and after surgery. Lead II and V5 are superior for arrhythmia detection and diagnosis. The blood pressure, temperature and arterial oxygen saturation also need to be monitored.

5. Adequate precautions should be taken during surgery to prevent the development of intra operative arrhythmias.

a. Surgical manipulations which can precipitate arrhythmias should be kept to the minimum.

b. Adequate depth of anaesthesia may prevent or control intra operative arrhythmias. 


\section{REVIEW ARTICLE}

c. Hypoxia, Hypotension and Hypovolemia due to blood loss should be prevented during surgery.1,4,7,8

Arrhythmia Related to Drugs during the Perioperative Period: Sevoflurane, halothane, and isoflurane can delay ventricular repolarization and prolong the QT interval. Isoflurane causes ventricular arrhythmias in $2.5 \%$ of patients; while desflurane increases the HR. Halothane sensitizes myocardium for exogenous catecholamines and can cause arrhythmias. Anesthetics that cause electrophysiological changes have the potential to cause arrhythmias and are on Table I.8,9

\begin{tabular}{|l|l|l|}
\hline \multicolumn{1}{|c|}{ Drug } & \multicolumn{1}{|c|}{ Action } & \multicolumn{1}{c|}{ Effects } \\
\hline Inhalational & $\begin{array}{l}\text { l Antagonize calcium and increase } \\
\text { depolarization in Purkinje fibers }\end{array}$ & $\begin{array}{l}\text { Junctional rhythm, } \\
\text { atrioventricular asynchrony }\end{array}$ \\
\hline Propofol & Stimulate muscarinic receptors & Bradycardia \\
\hline Succinylcholine & $\begin{array}{l}\text { Activate muscarinic or nicotinic } \\
\text { receptors }\end{array}$ & $\begin{array}{l}\text { Tachycardia or bradycardia, } \\
\text { it can lead to asystole }\end{array}$ \\
\hline Vecuronium & $\begin{array}{l}\text { Increase catecholamines and } \\
\text { automatism }\end{array}$ & $\begin{array}{l}\text { Tachycardia } \\
\text { blockade }\end{array}$ \\
\hline Local Anesthetics, & $\begin{array}{l}\text { Block calcium channels } \\
\text { rhythm }\end{array}$ \\
\hline Opioids & $\begin{array}{l}\text { Decrease frequency of the SA node } \\
\text { Prolong AV conduction }\end{array}$ & $\begin{array}{l}\text { Widening of the QRS, } \\
\text { Tachycardia, and VF }\end{array}$ \\
\hline Ketamine & $\begin{array}{l}\text { Increase SA node frequency by } \\
\text { sympathetic activation }\end{array}$ & Tachycardia \\
\hline $\begin{array}{l}\text { Clonidine and } \\
\text { Dexmedetomidine }\end{array}$ & Sympathetic blockade & Bradycardia \\
\hline \multicolumn{2}{|l|}{ Table I: Electrophysiological Changes of } & Anesthetics \\
\hline
\end{tabular}

Antiarrhythmic drugs can also cause arrhythmias. Anesthetist should have knowledge of drug interaction between anesthetics and antiarrythmic drugs to treat and prevent perioperative arrhythmias (table II). Drugs that induce bradyarrhythmias include digoxin, beta blockers, calcium channel blockers, amiodarone, clonidine, and dexmedetomidine. ${ }^{8}$

\begin{tabular}{|l|l|}
\hline \multirow{2}{*}{ Adenosine } & $\begin{array}{l}\text { Vasodilation with isoflurane and neuraxial block, } \\
\text { bronchoconstriction } \\
\text { with neostigmine, asystole with neostigmine, dexmedetomidine } \\
\text { and opioids, antagonism with aminophylline }\end{array}$ \\
\hline Amiodarone & Myocardial depression and vasodilation with inhalational agents \\
\hline Digoxin & $\begin{array}{l}\text { Bradycardia is potentiated by halothane and succinylcholine, Care } \\
\text { should be taken when administering calcium and using diuretics } \\
\text { (hypokalemia) }\end{array}$ \\
\hline
\end{tabular}




\begin{tabular}{|l|l|}
\hline Beta blocker, & $\begin{array}{l}\text { Myocardial depression is potentiated by halothane. } \\
\text { Bronchoconstriction with neostigmine and atracurium }\end{array}$ \\
\hline Quinidine & Prolongs the effects of neuromuscular blockers (NMB) \\
\hline Procainamide, & $\begin{array}{l}\text { Antagonizes neostigmine, Ventricular dysrhythmias when } \\
\text { combined with phenotiazides }\end{array}$ \\
\hline $\begin{array}{l}\text { Calcium channel } \\
\text { blocker, }\end{array}$ & $\begin{array}{l}\text { Bradycardia and myocardial depression with } \\
\text { halogenated agents and dantrolene, potentiates NMB. }\end{array}$ \\
\hline Magnesium & Prolongs the action of NMB \\
\hline Lidocaine & Potentiates the sympathetic blockade of opioids \\
\hline \multicolumn{2}{|c|}{ Table II:Interaction between Anesthetics and Antiarrhythmics } \\
\hline
\end{tabular}

Basic Science and Drug Pharmacology: Antiarrhythmic pharmacology is focused primarily on the cardiac ion channels and adrenergic receptors as drug targets. Although the molecular targets are distinctive, the drug receptor sites among the ion channel classes are highly homologous, causing some of the 'class overlap' (and clinical side-effects) associated with antiarrhythmic therapy.

Drug effects on the surface ECG can be predicted from their effects on the cardiac action potential, which in turn result from activity towards molecular targets (Fig. 2). The trajectory of the cardiac action potential is divided into five distinct phases, which reflect changes in the predominant ionic current flowing during the cardiac cycle.

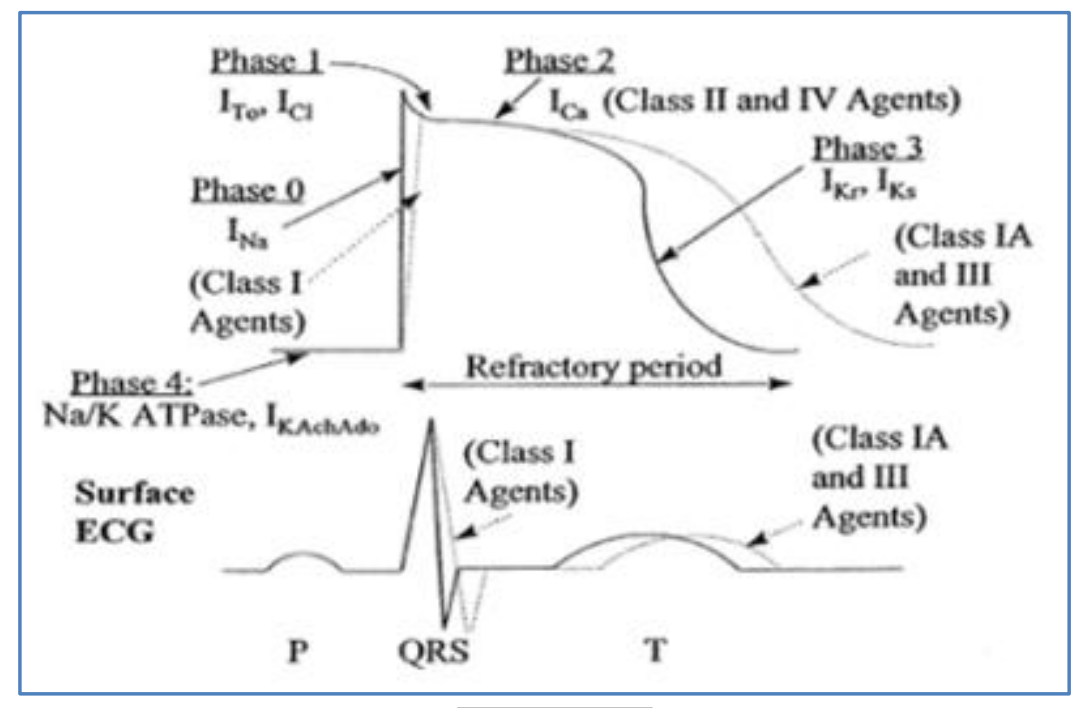

Fig. 2

Fig. 2: The action potential in ventricular muscle and its temporal relationship with the surface ECG.

The current responsible for 'phase 0 ', initial period of the action potential, initiates impulse conduction through the cardiac tissue. In the atria and ventricles, the impulse is initiated by $\mathrm{Na}^{+}$ current through $\mathrm{Na}^{+}$channels.

Hence, drugs that suppress $\mathrm{Na}^{+}$current (class I agents, Fig. 2) slow myocardial conduction and prolong the QRS complex and the P wave. In AV and SA nodal cells, phase 0 is produced by 
$\mathrm{Ca}^{2+}$ current through L-type $\mathrm{Ca}^{2+}$ channels. Drugs that suppress $\mathrm{Ca}^{2+}$ current therefore slow the atrial rate and also slow conduction through the AV node.

The latter effect prolongs the PR interval on the ECG, making the AV node a more efficient 'filter' for preventing rapid trains of atrial beats from passing into the ventricle.

The later phases of the action potential (phases 1, 2 and 3; Fig. 2) inscribe repolarization. The long plateau (phase 2) is maintained by $\mathrm{Ca}^{2+}$ current and is terminated (phase 3 ) by $\mathrm{K}^{+}$current. Hence, the QT interval on the ECG reflects the length of the action potential, and is determined by a delicate balance between these and many other smaller inward and outward currents.

Drugs that reduce $\mathrm{Ca}^{2+}$ current, namely those with class II or class IV activity, abbreviate the action potential plateau, shorten the QT interval and reduce the inward movement of $\mathrm{Ca}^{2+}$ into the cardiac cell. Hence, all agents that reduce $\mathrm{Ca}^{2+}$ current have the clinical potential to act as negative inotropes.

Conversely, agents with class IA or III activity block outward $\mathrm{K}^{+}$current, prolonging the action potential and the QT interval on the ECG. The electrophysiological manifestations of QT prolongation may be either therapeutic or arrhythmogenic.

During phase 4, the properties in SA and AV nodal tissue are again distinctive from those in atrial and ventricular muscle. Nodal cells spontaneously depolarize ('pace'), and activation of the adenosine A1 receptor triggers outward $\mathrm{K}^{+}$currents that hyperpolarize the nodal cell and oppose pacing. Since atrial and ventricular tissues are normally hyperpolarized, adenosine has little or no effect in these tissues. Adenosine also slows nodal conduction by inhibiting $\mathrm{Ca}^{2+}$ current through reducing cyclic AMP (cAMP). ${ }^{1,9-12}$

Antiarrhythmic agents principally used in anesthesiology and critical care are classified by functional effect according to the Vaughan Williams scheme 2 and is listed by their molecular targets. (Table III) ${ }^{12}$

\begin{tabular}{|l|c|l|}
\hline \multicolumn{1}{|c|}{ Receptor } & Class & \multicolumn{1}{c|}{ Drugs } \\
\hline $\mathrm{Na}^{+}, \mathrm{K}^{+}$channels & IA & Procainamide, quinidine, amiodarone \\
\hline $\mathrm{Na}^{+}$channels & IB & Lidocaine, phenytoin, mexiletine, tocainide \\
\hline Beta adrenoceptors & II & Esmolol, amiodarone, propranolol, atenolol, sotalol \\
\hline $\mathrm{K}^{+}$channels & III & Bretylium, ibutilidesotalol \\
\hline $\mathrm{Ca}^{2+}$ channels & IV & Verapamil, diltiazem, amiodarone \\
\hline Others & & Adenosine, digoxin \\
\hline \multicolumn{2}{|c|}{ Table III } \\
\hline
\end{tabular}

Pacemakers and implantable cardioverter defibrillators (ICD): Pacemaker and ICD placement has risen tremendously over the past few years and anesthetists will require a basic understanding of these devices in order to safely, effectively and expeditiously manage patients with pacemakers and ICD. The major peri-operative issue regarding pacemakers and ICDs is the risk of electromagnetic interference (EMI) from electrocautery or cardioversion.

EMI can result in inhibition of pacemaker output, activation of rate-responsive sensor resulting in increased pacing rate, ICD firing and myocardial injury at the lead tip resulting in failure to sense/capture or both. Except in urgent or emergent situations, management of pacemakers and ICDs in the peri-operative setting begins with the preoperative visit, which should include 
documentation of the patient's cardiac history, including the type of device, indication and date of device implantation and program details.1,9,13-15

MANAGEMENT OF PERIOPERATIVE ARRHYTHMIAS: The distinction between benign arrhythmia and those that carry the risk of sudden death is fundamental. The choice of anesthetic agents is important to minimize episodes of arrhythmias. While treating perioperative arrythmias, various causes or factors contributing should be searched and treatment started. Flowchart 1 gives a brief approach to perioperative arrhythmias.

Sinus Bradycardia: Sinus bradycardia indicates a sinus rhythm below $60 \mathrm{bpm}$.Cardiac causes of bradycardia includes sinus node dysfunction ('Sick Sinus Syndrome') or excess vagal stimulation. Surgery of the eye, raised intracranial pressure, surgery on cervical and mediastinal tumors, hypothyroidism and obstructive jaundice are other causes of sinus bradycardia.

Management consists of withdrawing or reducing the dose of the causal drugs, administration of Atropine $0.5 \mathrm{mg}$ intravenously or an intravenous infusion of Dopamine or Isoprenaline. Very seldom, cardiac pacing may be needed for severe sinus bradycardia.3, 4, 7

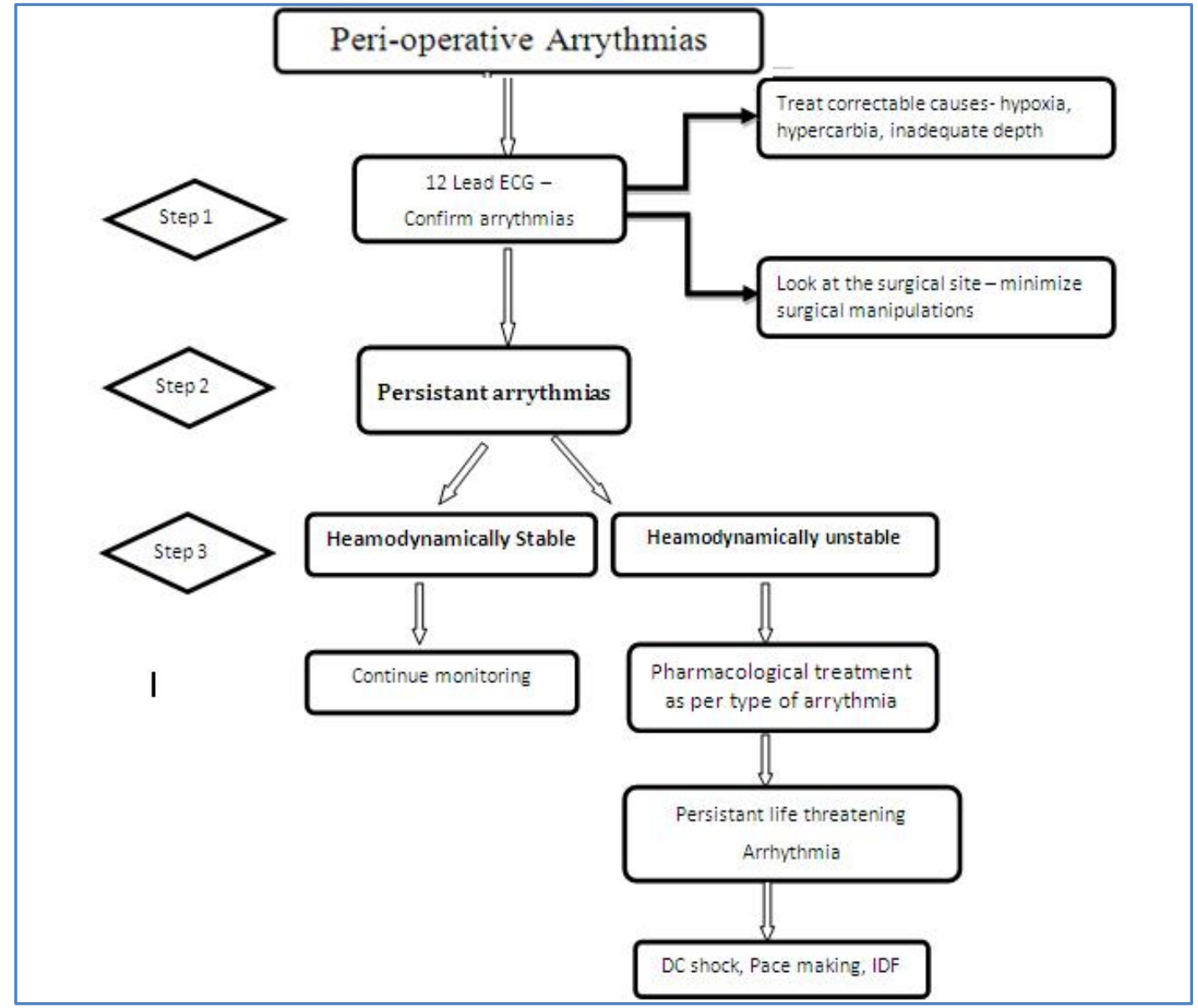

Sinus Tachycardia: Sinus tachycardia indicates a sinus rhythm above $100 \mathrm{bpm}$. Common factors causing sinus tachycardia are anxiety, pain, anemia, hypercarbia, hypoxia, hypotension, anesthetic agents, and other drugs like catecholamines, atropine, anti-depressants, fever and infection. 


\section{REVIEW ARTICLE}

Management consists of withdrawing the causal drugs, if any and correcting the factors responsible for the arrhythmia. Drugs like beta blockers, digoxin and verapamil may be used to control the rate. ${ }^{1,2,4,7}$

Premature Atrial Complexes [PAC]: Extrasystoles arising from the atria may be seen in normal individuals, in all types of heart diseases, sepsis, shock, inhalation agents, or excessive use of tobacco, caffeine and alcohol. Often PAC's need no treatment as they are self-limiting. But when they are in excess or compromise cardiovascular function, they are controlled with Beta blockers, Digitalis and calcium blockers like Verapamil or Diltiazem (intravenously or orally) after excluding the correctable causes.

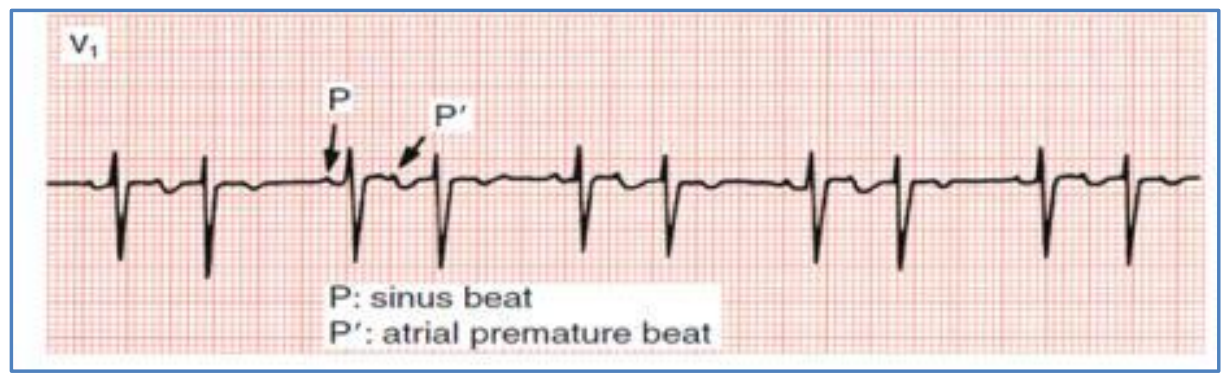

Fig. 3: Atrial premature beat.16

PAROXYSMAL SUPRAVENTRICULAR TACHYCARDIA [PSVT]: PSVT may be caused by Ectopic atrial tachycardia, where an abnormal atrial focus beats at a rate of $160-250 \mathrm{bpm}$ or may be caused by reentry in the AV node - AVNRT. Chronic obstructive pulmonary disease, digitalis toxicity, IHD and cardiomyopathy are common causes of this arrhythmia. Patients with the Pre-excitation syndrome are more prone for the re-entrant tachycardia. Occasionally normal individuals may develop PSVT during surgery or post operatively.

The majority of patients who develop intraoperative SVT remain hemodynamically stable and do not require cardioversion. Ventricular rate control is the mainstay of therapy. The advantages of slowing the ventricular rate during SVT are twofold. First, lengthening diastole serves to enhance left ventricular filling, thus enhancing stroke volume and improving hemodynamic stability. Second, slowing the ventricular rate reduces myocardial oxygen consumption and lowers the risk of cardiac ischaemia. $4,7,9$

\section{Management also includes:}

- Vagal manoeuvres like Carotid sinus massage, Valsalva maneuver or pharyngeal stimulation can abort the re-entrant variety of PSVT.

- Perioperative injection Adenosine given rapid intravenously in a dose of 6-12 mg often aborts a PSVT. Other drugs given intravenously are verapamil, diltiazem, digoxin and esmolol.

- When pharmacological approach fails, a synchronised DC cardioversion with 10 - 50 Joules can regress a PSVT to sinus rhythm.

- Temporary cardiac pacing at a rate over the tachycardia rate can override and abolish a PSVT. 


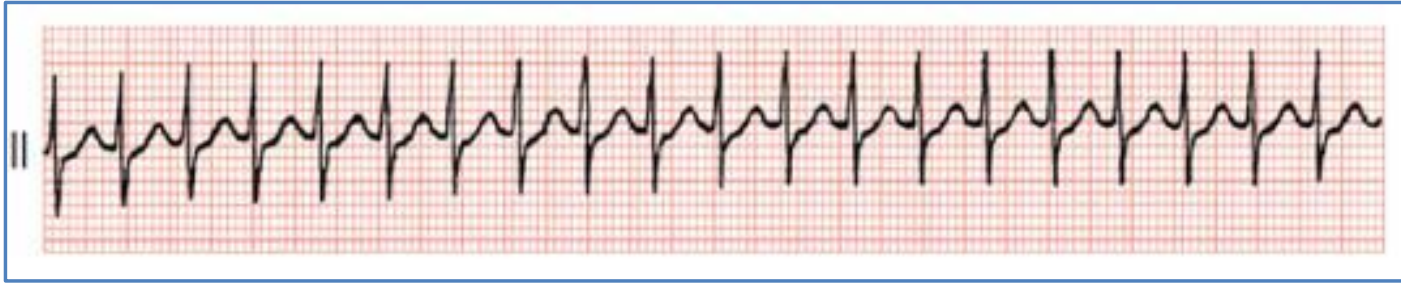

\section{Fig. 4}

ATRIAL FLUTTER: Atrial flutter is an ectopic atrial tachycardia with an atrial rate of 250 - 350bpm. The flutter waves are conducted with a $2: 1$ or $4: 1$ block and hence the ventricular rate may be 150 or $75 \mathrm{bpm}$. Atrial flutter is often associated with myocardial, pericardial diseases and thyrotoxic individuals which may degenerate into atrial fibrillation.

- Synchronised DC conversion using a current of 50 Joules or less is the treatment of choice for atrial flutter.

- Alternatively, Verapamil 5 - $10 \mathrm{mg}$ IV or Diltiazem $0.25 \mathrm{mg} / \mathrm{kg}$ slow IV may abolish the flutter.

- Esmolol, given in a dose of $200 \mathrm{mcg} / \mathrm{kg} / \mathrm{min}$ slow intravenously may be tried.

- Digoxin $0.5 \mathrm{mg}$ given IV slows the rate of the flutter and then reverts to normal sinus rhythm.

- Very seldom, rapid atrial pacing may be needed to abolish atrial flutter.2,4

Fig. 5: P waves more than $300 / \mathrm{min}$ giving sawtooth appearance, ventricular rate $60 / \mathrm{min}$.

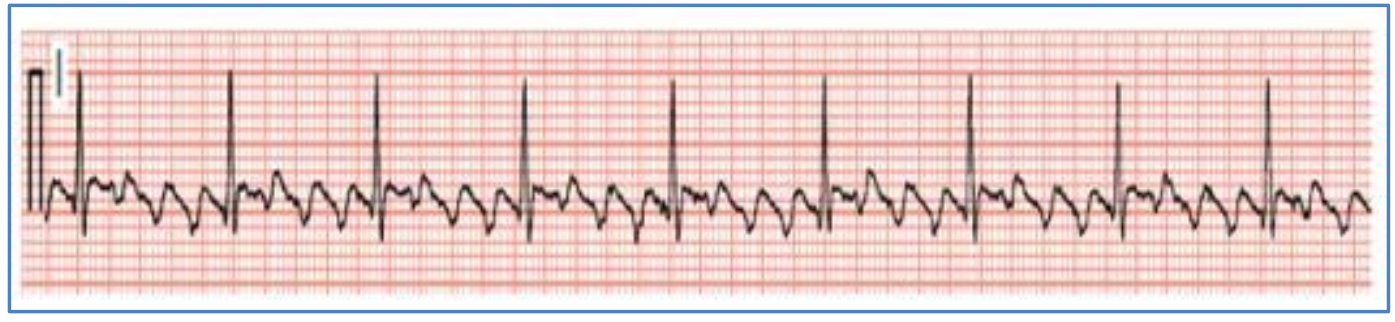

Fig. 5

ATRIAL FIBRILLATION: In atrial fibrillation, P waves are absent in the ECG to be replaced by coarse fibrillary waves. The rate of the fibrillary waves is often as high as 450 - 600 per minute and the ventricular response is irregular and rapid.

Patients with rheumatic valvular diseases, Systemic hypertension, Congestive cardiac failure and myocardial diseases are more prone to develop atrial fibrillation. Advanced age, Thyrotoxicosis and alcoholism are other causes of atrial fibrillation:

- Sudden onset atrial fibrillation can often be reverted with synchronised DC conversion using 50 - 100 Joules.

- Digoxin 0.5 - $1 \mathrm{mg}$ IV may be given to slow the ventricular response and convert atrial fibrillation to sinus rhythm.

- Other drugs that can be given IV are Verapamil, Diltiazem, Amiodarone and Procainamide. 
- Chronic atrial fibrillation present prior to surgery is often more resistant to drugs and DC shock treatment and often recurs. In this setting pre-operatively drugs like beta blockers, digitalis or verapamil are used to control the ventricular rate prior to surgery.

The occurrence of embolic phenomena is high in patients with atrial fibrillation and hence need to be anticoagulated. Pre-operatively, however, these patients need to be weaned off anticoagulants and their coagulation profile studied prior to surgery. Postoperatively, heparin may be given or oral anticoagulants restarted after convalescence. ${ }^{17-21}$

Fig. 621: Atrial fibrillation - no P waves, irregular baseline, irregular QRS complexes.

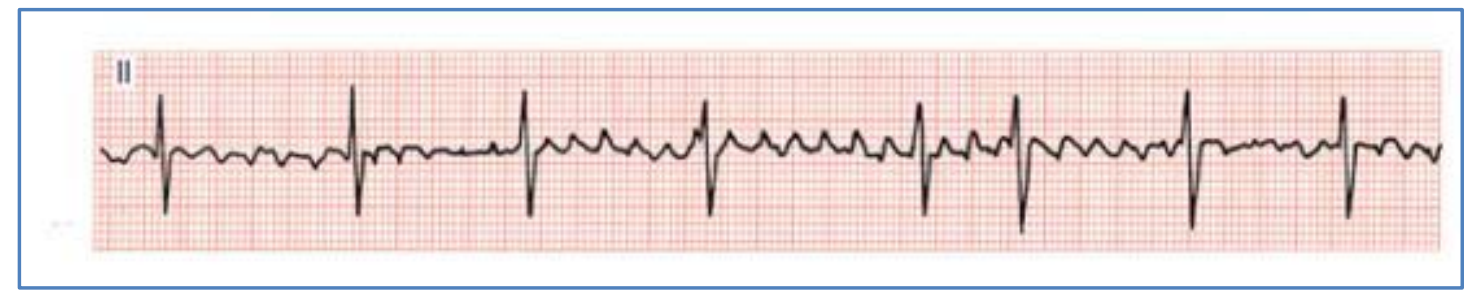

Fig. 6

VENTRICULAR PREMATURE COMPLEXES [VPC]: VPC's are often the commonly seen arrhythmias during the peri-operative period and can be caused by cardiac and non-cardiac factors like electrolyte imbalances, hypoxia, hypercarbia, anesthetic agents, tobacco, caffeine, alcohol, sympathomimetic drugs and antidepressant drugs. VPC's also commonly occur during cardiac, thoracic and gastrointestinal surgery.

Occasionally VPC's are induced when the heart rate is very slow (Bradycardia induced VPC's).Here, Atropine IV may abolish the VPC's by accelerating the heart.

Management Includes:

- Correcting the underlying cause and Lignocaine 50 - $75 \mathrm{mg}$ IV as a bolus dose followed by an IV infusion of 1 - $4 \mathrm{mg} / \mathrm{min}$ is the drug of choice.

- Amiodarone $150 \mathrm{mg}$ given over 10 minutes slow intravenously is also helpful.

- Propranolol, Procaineamide and Quinidine are other drugs that can be given IV to abolish VPC's.

Oral drugs may be started in the post-operative phase if the ectopics persist. Beta blockers, Verapamil, Amiodarone, Disopyramide or Quinidine may be given.

VENTRICULAR TACHYCARDIA [VT]: VT is a dangerous arrhythmia as it can degenerate into Ventricular flutter or ventricular fibrillation. Hence the management of precipitating factors like hypoxia, ischemia, hypoglycemia, hypotension and electrolyte imbalances assume great importance. Ventricular arrhythmias can be subdivided according to their morphology (monomorphic vs. polymorphic) and their duration (sustained vs. non-sustained).

Non-sustained ventricular tachycardia (NSVT) is defined as three or more premature ventricular contractions that occur at a rate exceeding 100 beats.min $^{-1}$ and last 30 s or less without 
hemodynamic compromise. These arrhythmias are routinely seen in the absence of cardiac disease and may not require drug therapy in the peri-operative period.9, 16, 17

Sustained VT generally falls into one of two categories: Monomorphic and Polymorphic:

- Lidocaine has traditionally been the primary drug therapy for all sustained ventricular arrhythmias

- Recent studies have shown IV procainamide to be more effective than IV lidocaine (50-100mg IV over $5 \mathrm{~min}$ ) followed by a lidocaine infusion (2-4 mg.min ${ }^{-1} \mathrm{IV}$ ).

- Other drugs like bretylium or amiodarone may be used; however IV amiodarone has been shown to be as effective as bretylium with added advantage of less hypotension as compared to IV bretylium.

- Sustained VT can be cardioverted with a synchronised DC shock of 120 - 200J. Following cardioversion, the patient needs to be on a continuous intravenous infusion of lignocaine for 24 - 48 hours to prevent recurrences.

- Occasionally, ventricular pacing may be required to abort the arrhythmia.

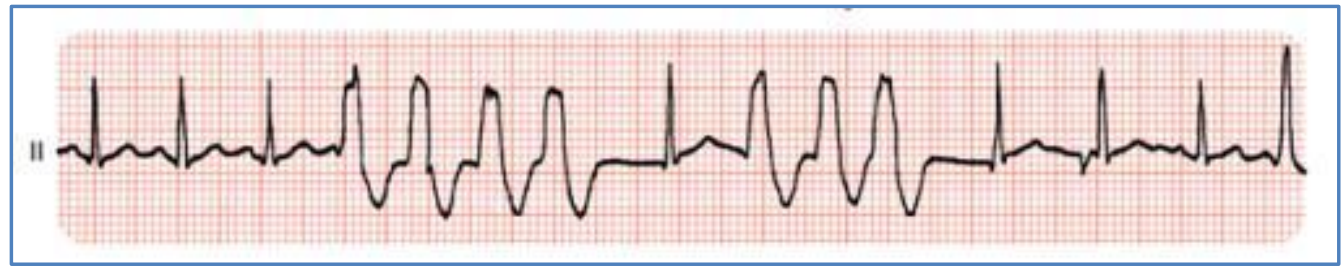

Fig. 7

Torsades de pointes (Tdp): Tdp ("twisting of the points") is an atypical polymorphic form of VT characterized by beat-to beat variation, prolonged QT interval, and a constantly changing/twisting QRS axis around the baseline (figure 8). A severe non-uniform delay in repolarization, illustrated by QT prolongation, is the primary electrophysiological derangement. It begins with a distinguishing long-short initiating sequence. It can be induced by the following causes:

- Metabolic: Hypokalaemia, hypomagnesaemia

- Drugs: Phenothiazine, procainamide, quinidine, dispyramide

- Cardiac: acute ischemia, infarction.

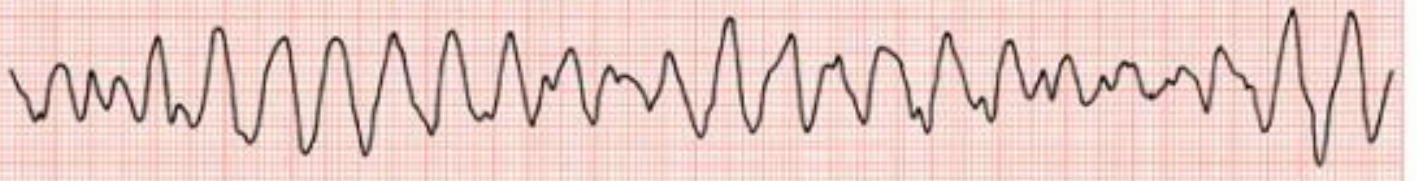

Fig. 8

The management of Tdp is initially aimed at correcting the underlying cause and a bolus of $2 \mathrm{~g}$ magnesium sulphate as emergency cellular membrane stabilizing treatment. Further therapy preferentially includes overdrive atrial pacing if AV conduction is intact, before ventricular pacing. 


\section{REVIEW ARTICLE}

Ventricular fibrillation (VF): VF is very rapid and irregular ventricular activity with no mechanical effect. Causes include myocardial ischemia, aberrant foci, VT, Tdp, hypoxemia, electrolyte imbalance and drug effects. ECG shows ill-defined QRS complexes, shapeless rapid oscillations and on pulse oximetry, there is acute fall in SpO2 because of low or no cardiac output.

Treatment includes Cardiopulmonary resuscitation started as soon as possible. Asynchronous external defibrillation using 200-360J may revert VF. Intravenous bretylium 5-10 mg.kg-1 over $5 \mathrm{~min}$ can be useful on some occasion. ${ }^{16,18,21}$

Fig. 9:Ventricular fibrillation.

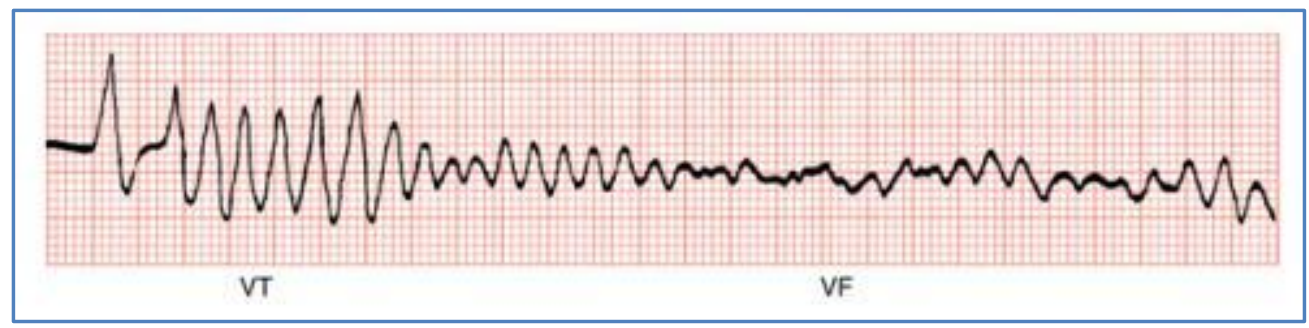

Fig. 9

\section{HEART BLOCK:}

Sino-atrial blocks manifest as periods of sinus arrest or dropped sinus beats. They are managed as mentioned under 'sinus bradycardia'.

Atrio-ventricular blocks (AV blocks) are of three types:

1. First degree $A V$ block manifests as a prolongation of the P-R interval and often needs no treatment apart from careful monitoring. Any causal drugs like digoxin, beta blockers or verapamil may be withdrawn or reduced.

2. Second degree AV block can be of two types.

- Mobitz type I AV block- where the P-R interval progressively lengthens to be followed by a blocked $\mathrm{P}$ wave, resulting in a dropped beat.

- Mobitz type II AV block- where the P-R interval is fixed with occasional dropped beats occurring. Occasionally every alternate $\mathrm{P}$ wave is blocked giving rise to a 2:1 block.

Fig. 10: Second degree heart block (wenkebach type) - progressive lengthening of PR interval with one non-conducted beat.

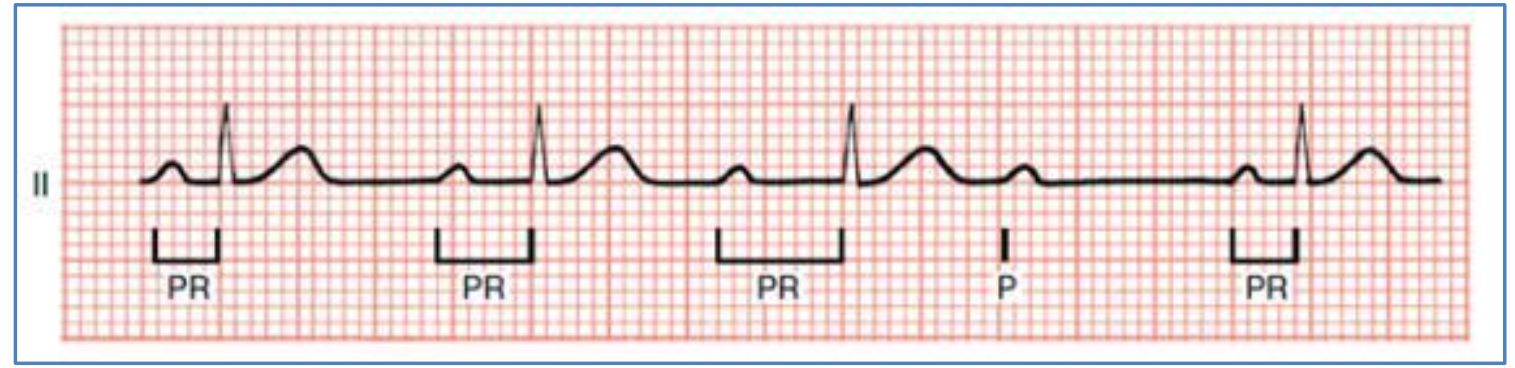

Fig. 10 
3. Third degree or Complete AV Block- where no conduction to ventricles occur and hence the atria beat at a normal rate of $60-100 \mathrm{bpm}$ and the ventricle is controlled by an idioventricular rhythm at $20-40 \mathrm{bpm}$.

- Isoprenaline infusion intravenously accelerates the idioventricular rhythm and helps to tide over the acute phase.

- Ventricular pacing is required to maintain hemodynamic stability.

Patients with chronic complete heart block need temporary or permanent pacing prior to surgery in order to prevent adverse cardiovascular disturbances during the peri-operative period.

Fig. 11:Third degree heart block- no relationship P waves and the QRS complexes.

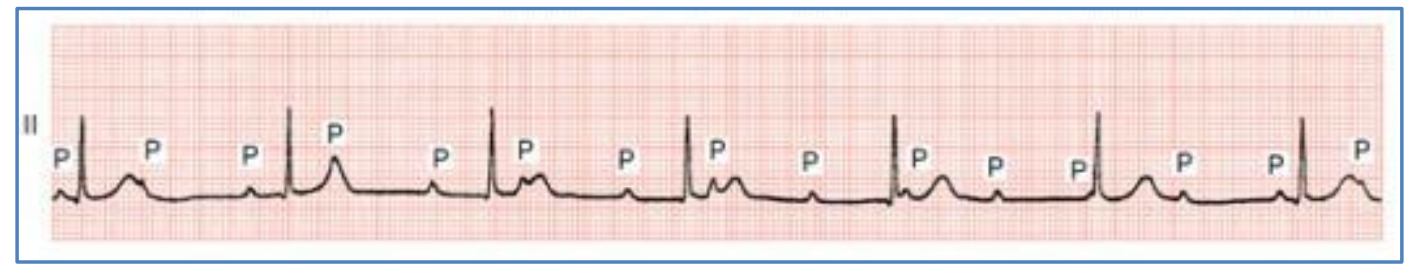

\section{Fig. 11}

Left bundle branch block is often associated with severe heart disease than Right bundle branch block and the chances of arrhythmias and complete heart block is higher in these patients. ${ }^{3,13,15,18}$

SUMMARY: Cardiac arrhythmias remain a major source of morbidity, mortality, and prolonged postoperative hospital stay in surgical patients. All patients undergoing even minor surgical procedures should be ideally monitored continuously during and after surgery. The proper preoperative assessment and choice of an appropriate anesthetic agent or technique prevents perioperative arrhythmias.

Intra-operative arrhythmias may be prevented by prompt correction of hypoxia, acidosis, adequate analgesia, hypotension and careful surgical manipulations. Therefore, the knowledge of cardiac arrhythmias and triggering factors, allows the anesthesiologist a better approach of the perioperative period by avoiding wrong or unnecessary treatment further can be better managed in conjunction with a cardiologist.

\section{REFERENCES:}

1. Kaplan JA, Reich DL, Savino JS, et al., eds. Kaplan's Cardiac Anesthesia. 6th ed. Philadelphia: Elsevier Saunders; 2011: 74-93.

2. The American Heart Association in Collaboration with the International Liaison Committee on Resuscitation (ILCOR): Guidelines 2010 for cardiopulmonary resuscitation and emergency cardiovascular care. Circulation 2010; 122:S250.

3. Fauci AS, Braunwald E, Kasper DL, et al., eds .Harrison's principles of internal medicine, Disorders of rhythm, chapter 231-3, 18th ed. 2012, McGraw-Hill, 1860-1901.

4. N Dua, VP Kumra. Management of Perioperative Arrhythmias. Indian Journal of Anaesthesia 2007; 51 (4): 310-323. 
5. Alessia Pedoto, David Amar. Perioperative Arrhythmias and Acute Right Heart Failure in Noncardiac Thoracic Surgery. Curr Anesthesiol Rep (2014) 4:142-149 DOI 10.1007/s40140014-0055-8.

6. Kumar P Clark M.Clinical Medicine. 3rd eds. Cardiac arrhythmias 1994. ELBS 554-555, 566568.

7. Hines \& Marschall: Abnormalities of cardiac conduction and cardiac rhythm, In: Stoelting's Anesthesia and Co-Existing Disease, 5th ed. churchill Livingston 2008, 61-85.

8. Michelle Nacur Lorentz, Bruna Silviano Brandão Vianna. Cardiac dysrhythmias and Anesthesia, Rev Bras Anestesiol, 2011; 61: 6: 798-813.

9. A. Thompson, J R Balser. Perioperative cardiac arrhythmias, Br. J. Anaesth. (2004) 93 (1): 8694.doi: 10.1093/bja/aeh166.

10. Priori SG, Barhanin J, Hauer RN, et al. Genetic and molecular basis of cardiac arrhythmias: impact on clinical management parts I and II. Circulation 1999; 99: 518-28.

11. Engelstein ED, Lippman N, Stein KM, Lerman BB. Mechanism specific effects of adenosine on atrial tachycardia. Circulation 1994; 89: 2645-54.

12. Vaughan Williams EM. A classification of antiarrhythmic actions reassessed after a decade of new drugs. J Clin Pharmacol 1984; 24:129-47.

13. Gregoratos G, Abrams J, Epstein AE, Freedman RA, Hayes DL, Hlatky MA, et al. ACC/AHA/NASPE 2002 guideline update for implantation of cardiac pacemakers and antiarrhythmia devices: summary article: a report of the American College of Cardiology/American Heart Association Task Force on Practice Guidelines (ACC/AHA/NASPE Committee to Update the 1998 Pacemaker Guidelines). Circulation 2002; 106: 2145-61.

14. The American Heart Association, in collaboration with the International Liason Committee on Resuscitation Guidelines 2000 for Cardiopulmonary Resuscitation and Emergency Cardiovascular Care. Part 6: advanced cardiovascular life support 7D: the tachycardia algorithms. Circulation 2000; 102:1158-65.

15. Salukhe TV. Dob D, Sutton R. Pacemakers and defibrillators: anaesthetic implication. Br J Anaesth 2004; 93; 95-104.

16. Ary L Goldberger. Goldbergers clinical electrocardiography, $8^{\text {th }}$ ed. Philadelphia: Elsevier Saunders, 2013: 59-70,138-172.

17. Singh SN, Fletcher RD, Fisher SG, et al. Amiodarone in patients with congestive heart failure and asymptomatic ventricular arrhythmia. N Engl J Med 1995; 333: 77-82

18. Vaughan Williams EM. A classification of antiarrhythmic actions reassessed after a decade of new drugs. J Clin Pharmacol 1984; 24: 129-47

19. Stoelting RK, Hillier SC. Cardiac antidysrhythmic drugs. In: Pharmacology and Physiology in Anesthetic Practice, $4^{\text {th }}$ ed. Philadelphia: Lippincott Williams \& Wilkins, 2006: 370-386.

20. Hastings LA, Balser JR. New treatments for perioperative cardiac arrhythmias, Anesthesiol Clin North America. 2003 Sep; 21(3):569-86.

21. January CT, Wann LS, Alpert JS, Calkins H, Cleveland JC, Cigarroa JE et al. 2014 AHA/ACC/HRS guideline for the management of patients with atrial fibrillation: a report of the American College of Cardiology/American Heart Association Task Force on Practice Guidelines and the Heart Rhythm Society. Circulation 2014; 129. 


\section{REVIEW ARTICLE}

\section{AUTHORS:}

1. Savitri D. Kabade

2. Gowri Shankar B.

3. Venkatesh Y.

\section{PARTICULARS OF CONTRIBUTORS:}

1. Associate Professor, Department of Anaesthesiology, KIMS, Hubli, Karnataka, India.

2. Post Graduate, Department of Anaesthesiology, KIMS, Hubli, Karnataka, India.

3. Post Graduate, Department of Anaesthesiology, KIMS, Hubli, Karnataka, India.

\section{NAME ADDRESS EMAIL ID OF THE CORRESPONDING AUTHOR:}

Dr. Savitri D. Kabade,

Karnataka Institute of Medical Sciences,

KIMS Campus,

Vidyanagar, Hubli-580022,

Karnataka, India.

Email: sampradakabade@gmail.com

Date of Submission: 25/07/2014.

Date of Peer Review: 26/07/2014.

Date of Acceptance: 08/08/2014.

Date of Publishing: 20/08/2014. 